\title{
Accelerated sea level rise and Florida Current transport
}

\author{
J. Park ${ }^{1}$ and W. Sweet ${ }^{2}$ \\ ${ }^{1}$ National Park Service, Everglades National Park, 950 N Krome Ave, Homestead, FL, USA \\ ${ }^{2}$ National Oceanic and Atmospheric Administration, 1305 East West Hwy, Silver Spring, MD, USA
}

Correspondence to: J. Park (joseph_park@nps.gov)

Received: 24 March 2015 - Published in Ocean Sci. Discuss.: 30 April 2015

Revised: 28 June 2015 - Accepted: 16 July 2015 - Published: 30 July 2015

\begin{abstract}
The Florida Current is the headwater of the Gulf Stream and is a component of the North Atlantic western boundary current from which a geostrophic balance between sea surface height and mass transport directly influence coastal sea levels along the Florida Straits. A linear regression of daily Florida Current transport estimates does not find a significant change in transport over the last decade; however, a nonlinear trend extracted from empirical mode decomposition (EMD) suggests a $3 \mathrm{~Sv}$ decline in mean transport. This decline is consistent with observed tide gauge records in Florida Bay and the straits exhibiting an acceleration of mean sea level (MSL) rise over the decade. It is not known whether this recent change represents natural variability or the onset of the anticipated secular decline in Atlantic meridional overturning circulation (AMOC); nonetheless, such changes have direct impacts on the sensitive ecological systems of the Everglades as well as the climate of western Europe and eastern North America.
\end{abstract}

\section{Introduction}

The Florida Current is a progenitor of the Gulf Stream, a component of the North Atlantic subtropical gyre western boundary current, and a surface component of the Atlantic meridional overturning circulation (AMOC). This current is climatically important (Jackson et al., 2015) with model simulations predicting a decrease in AMOC in response to increasing greenhouse gases (Solomon et al., 2007; Liu et al., 2015). Models also suggest the potential for significant mean sea level (MSL) changes across the western North Atlantic in response to AMOC dynamics (Brunnabend et al., 2014). In terms of mass transport Thomas et al. (2012) found that a weakening AMOC would be manifested as a reduction in southward deep water transport balanced by a decline in the northward upper ocean western boundary current. A decrease in AMOC since 2004 has been reported by Robson et al. (2014) and Smeed et al. (2014), finding a weakening of the southward flowing lower North Atlantic deep water. It is then reasonable to expect a concurrent decrease in western boundary transport.

The Florida Current is not only important in terms of meridional heat transport but also tightly confined in the Straits of Florida, and a geostrophic balance between transport and western boundary sea surface height exert a significant influence on coastal sea levels as noted by Montgomery (1938). More recent investigations corroborate the transportMSL link, e.g., Blaha (1984); Sweet et al. (2009), and quantify transport variations (Leaman et al., 1987). It should be noted that there are a multitude of dynamical processes acting in concert with the transport-MSL mechanism, such as regional wind stress, barometric pressure, and bottom friction on the shelf 1, although in South Florida the shelf is narrow and frictional effects are minimal. These coastal sea level variations have important implications on ecological and anthropogenic responses along the Florida Straits and eastern seaboard of North America, including the fresh water resources of the environmentally critical ecosystems of the Everglades.

Gulf Stream dynamics in the Middle Atlantic Bight of North America (between Cape Hatteras and Cape Cod) is known to express similar influences on MSL (Thompson et al., 2014; Goddard et al., 2015). For example, Woodworth et al. (2014) related AMOC and wind stress to MSL finding that wind stress dominates at interannual and shorter timescales. Ezer et al. (2013) analyzed the MSL elevation gradient across the western boundary of the Gulf Stream, Florida Current transport, and coastal sea level at 10 tide 


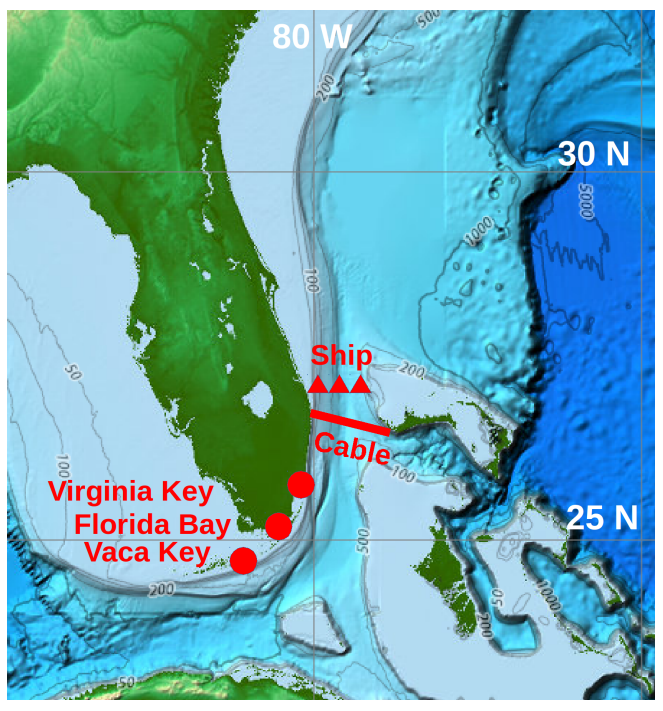

Figure 1. Map of Florida Straits with the cable, tide gauge, and ship measurement locations. Bathymetry contours are in meters.

gauges in the Chesapeake Bay and middle Atlantic coast concluding that the Gulf Stream has shifted from a 6-8 year oscillation cycle to a continuous weakening trend since about 2004, and that this trend may be responsible for a recent acceleration of middle Atlantic coast sea level rise (Sallenger et al., 2012). Subsequently, Rossby et al. (2014) reported 2 decades of ship-based velocity measurements across the Gulf Stream finding no significant decrease based on a linear regression. We note that Ezer et al. (2013) based their results on empirical mode decomposition (EMD), a component of the Hilbert-Huang transform (Huang and $\mathrm{Wu}, 2008$ ) capable of extracting nonlinear trends, in an area limited to the US east coast, while Rossby et al. (2014) analyzed stream-wide transects from the east coast to Bermuda. More recently, Ezer (2015) re-examined this apparent tension finding that the contrasting results are actually consistent when one considers the nonlinear nature and spatial dependence of the data.

The question of which statistical estimator is appropriate for a given data set is important. When dealing with multidimensional geophysical signals which have significant variance not only due to random process noise but also include nonlinear, nonstationary components across a range of timescales, linear regression over a long period is perhaps not appropriate (Wu et al., 2007). In the case of Florida Current and MSL variability, we suggest that a single coefficient over multiple decades is not appropriate to capture time-varying trends such as the recent decline in AMOC and acceleration of mean sea level. Instead, we employ EMD to extract timedependent trends in Florida Current transport and mean sea level.

EMD is a heuristic, basis-free, data-adaptive modal decomposition which extracts modes in order of increasing oscillatory scales (lower instantaneous frequencies) into intrin- sic mode functions (IMFs). It is essentially a modern implementation of Chrystal's graphical method of residuation (Chrystal, 1906), with an excellent introduction and review provided by Huang and $\mathrm{Wu}$ (2008). In contrast to Fourier decomposition employing time-invariant sinusoidal bases, wavelet transforms using scale-invariant wavelets, or empirical orthogonal functions based on eigenmodes, EMD is a recursive residuation extracted from envelopes of the data itself. It performs well on non-stationary and nonlinear signals, and is suited to the extraction of time-adaptive nonlinear trends (Wu et al., 2007). However, as with any analysis technique it has limitations which can include mode mixing where different IMFs may contain portions of a signal with the same temporal scale. The mode-mixing problem can be resolved with ensemble empirical mode decomposition, the reader is referred to Huang and $\mathrm{Wu}$ (2008) for a complete discussion, although in our analysis we focus on the EMD residuals and decadal-scale IMFs where there is no evidence of mode mixing.

The question of whether or not recent changes in Florida Current and AMOC transport are secular has not yet been answered. Kopp (2013) examined tide gauge records along the middle Atlantic coast together with the Atlantic Multidecadal Oscillation (AMO) and North Atlantic Oscillation (NAO) indices, finding that all are currently within the bounds of 20th century variability and that another decade of observations are required to determine whether the recent middle Atlantic coast sea level acceleration represents the onset of trend, or an extension of historical variability. Specific to sea level rise acceleration, Haigh et al. (2014) indicate that interannual to multidecadal variability dominates the records such that in most locations several additional decades are needed to reliably quantify any tide gauge accelerations.

\section{Transport estimates}

Daily transport estimates derived from electromotive induction voltages in a submarine cable spanning the Florida Straits near $27^{\circ} \mathrm{N}$ have been made since 1982 (Fig. 1), with independent ship-based calibration measurements obtained on a recurring basis. A review of Florida Current transport measurements including details on the cable observational program and data can be found in Meinen et al. (2010) along with an assessment of the temporal variability of Florida Current transport. Specifically, two-thirds of the variance is at sub-annual timescales, less than $10 \%$ annually, $13 \%$ interannually (13-42 months), and less than $10 \%$ at periods longer than 42 months. Meinen et al. (2010) also found no evidence for a long-term linear trend in Florida Current transport based on data for 1982-2007, and variability on decadal timescales of roughly \pm 1 Sv during 1982-2007.

Garcia and Meinen (2014) recently assessed accuracy of the cable transport estimates, finding that annual transport averages are accurate to within $0.3 \mathrm{~Sv}$ and that the cable is capable of observing small but important climate-induced 
Table 1. IMF minimum and maximum instantaneous frequency expressed as periods in years.

\begin{tabular}{|c|c|c|c|c|c|c|c|c|}
\hline \multicolumn{3}{|c|}{ Florida Current } & \multicolumn{3}{|c|}{ NAO } & \multicolumn{3}{|c|}{ MEI } \\
\hline IMF & $\begin{array}{r}\min \\
(\mathrm{yr})\end{array}$ & $\begin{array}{r}\max \\
(\mathrm{yr})\end{array}$ & IMF & $\begin{array}{l}\min \\
(\mathrm{yr})\end{array}$ & $\begin{array}{r}\max \\
(\mathrm{yr})\end{array}$ & $\mathrm{IMF}$ & $\begin{array}{r}\min \\
(\mathrm{yr})\end{array}$ & $\begin{array}{c}\max \\
(\mathrm{yr})\end{array}$ \\
\hline 11 & 0.41 & 3.57 & 7 & 3.25 & 10.67 & 4 & 0.75 & 3.92 \\
\hline 12 & 0.62 & 4.93 & 8 & 5.92 & 14.08 & 5 & 1.17 & 4.92 \\
\hline 13 & 0.99 & 4.52 & 9 & 7.75 & 16.08 & 6 & 1.92 & 6.25 \\
\hline 14 & 1.82 & 6.45 & & & & 7 & 3.58 & 6.83 \\
\hline 15 & 2.97 & 7.22 & & & & & & \\
\hline 16 & 5.88 & 12.51 & & & & & & \\
\hline 17 & 9.93 & 15.26 & & & & & & \\
\hline
\end{tabular}

changes in Florida Current transport. The focus of this paper is to examine recent data linking Florida Current transport and coastal MSL anomalies from a nonlinear, time-varying trend perspective.

\section{Florida Current trend}

Daily estimates of Florida Current transport from the cable, as well as ship-based dropsonde or lowered acoustic Doppler profiler measurements are available from the NOAA Climate Observation Division as part of the Western Boundary Time Series project (NOAA, 2015a). Figure 2a shows daily data from 18 March 1982 to 19 November 2014 along with data reconstruction (gray vertical bands) over the period 23 October 1998 through 18 June 2000 when data were not collected, and five other periods with gaps greater than 30 days ( 2 July to 16 August 1995; 27 May to 8 August 1996; 21 November 2001 to 2 February 2002; 2 September to 8 October 2001; 3 September to 29 October 2004).

The reconstructed data are uniformly sampled from distributions constructed from all available data for a missing yearday. For example, if 1 January 2000 is missing, a Gaussian kernel is fit to all available data for 1 January. A uniform random sample is then drawn from this distribution and used as the reconstructed value. This preserves the overall distribution of the data for a yearday capturing the seasonal trends, while realistically allowing for variance away from the mean on the daily timescale. All other data gaps (46 one day gaps, 33 between 2 and 5 days, 21 between 6 and 30 days) are filled with linear interpolation. The ship data have no reconstruction applied.

A linear regression of the ship data with time results in a decline of $0.77 \pm 0.55 \mathrm{~Sv}$ from 1982 to 2014 with a $p$ value of 0.17 , suggesting an $83 \%$ probability that a linear model decline is not a random artifact. A linear model of cable transport from 1982 to September 2014 finds a decrease of $1.08 \pm 0.11 \mathrm{~Sv}$ ( $p$ value less than 0.001 ), while from October 2004 to October 2014 a linear regression decrease of $0.57 \pm 0.19 \mathrm{~Sv}$ ( $p$ value 0.002 ) is obtained. Since decadal transport variability of the Florida Current has been esti-

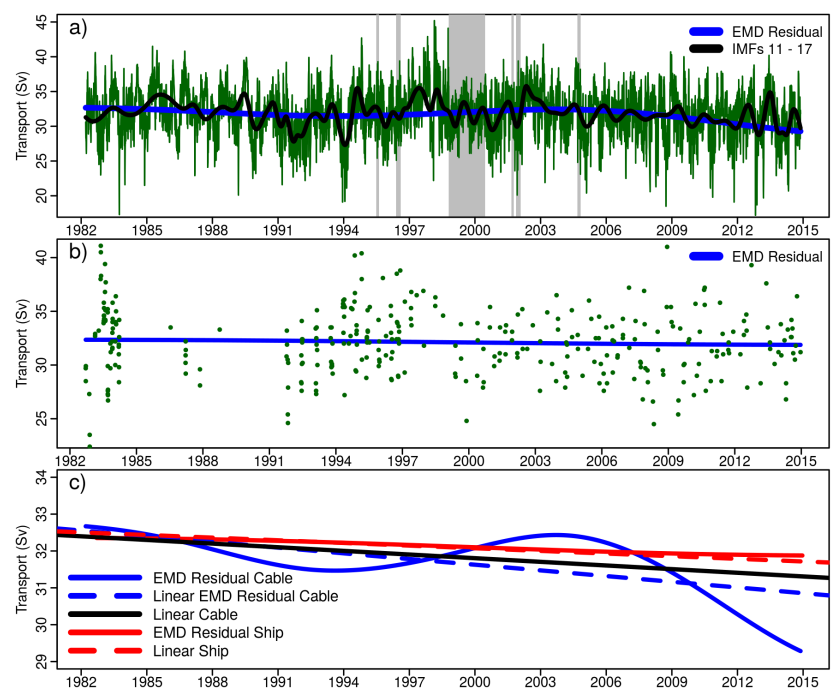

Figure 2. (a) Florida Current daily transport estimates from induced cable voltages at $27^{\circ} \mathrm{N}$ (green). The gray background bounds missing measurements and data reconstructed from daily distributions across all available years. Also shown are the sum of the EMD residual and IMFs 11-17 (black), and the EMD residual itself (blue). The total number of IMFs is $N_{\mathrm{IMF}}=17$. (b) Florida Current transport estimates from ship-based measurements (green) and EMD residual (blue). (c) Comparison of EMD residuals to linear models of the transport data, and to a linear model of the cable transport EMD residual.

mated as $\pm 1 \mathrm{~Sv}$ (Meinen et al., 2010), linear regressions of the data, which are less than $1 \mathrm{~Sv}$ decade $^{-1}$, can lead one to conclude that there has been no significant change in mean transport.

However, a linear model can be biased by incomplete modal oscillations, is not data adaptive within the record (there is only one fit coefficient), and may provide an incomplete picture for the complex dynamics of coupled nonlinear processes, providing motivation to employ EMD in an effort to extract time-varying trends in the data. The black line in Fig. 2a shows the sum of the cable data EMD residual with IMFs 11 through 17 which are the seven longest temporal scale, or lowest instantaneous frequency modes, while the blue line plots the EMD residual representing the trend. IMFs are not restricted to a constant frequency of oscillation, and Table 1 lists the range of oscillation periods (inverse of instantaneous frequency) for the IMFs discussed in this paper. The trend in cable data from 1982 through 2004 exhibits a $\pm 1 \mathrm{~Sv}$ variation, while the most recent decade indicates a $3 \mathrm{~Sv}$ decline. Figure $2 \mathrm{~b}$ shows the ship data with its EMD residual, which in contrast to the cable data exhibits a mildly declining trend.

A comparison of transport data EMD residuals with linear models is shown in Fig. 2c. The dashed blue line shows a linear regression of the cable data EMD residual, although in practice it makes little sense to linearize a nonlinear trend, 
Table 2. Linear models of Florida Current transport rates and change over the period of record (March 1982-November 2014) from ship and cable data.

\begin{tabular}{rrr}
\hline Data & Rate $\left(\mathrm{Sv} \mathrm{yr}^{-1}\right)$ & Change (Sv) \\
\hline Ship data & $-0.024 \pm 0.017$ & $-0.772 \pm 0.555$ \\
Cable data & $-0.033 \pm 0.003$ & $-1.077 \pm 0.105$ \\
Cable EMD residual & $-0.051 \pm 0.001$ & $-1.625 \pm 0.019$ \\
\hline
\end{tabular}

while the dashed red line is a linear regression of the ship data, and the solid black line a linear regression of the cable data. The ship data EMD residual and linear regressions are nearly degenerate, whereas the cable EMD residual is time dependent and significantly different from the corresponding linear trend, although both suggest a general decline in transport over the period of record. Table 2 presents a comparison of the linear models suggesting that there is not a great disparity between the linear model decline of the cable data and a linear model of the cable EMD residual. However, Fig. 2c does illustrate the considerable difference in trends for the cable data when considering a linear vs. a time-varying nonlinear model.

The remarkable divergence between the ship-based and cable transport estimates over the last decade has not been attributed and needs further study. One factor is that the cable estimates are based on an integrated measurement of electromotive flux across the entire cable, whereas ship measurements are sampled with spatially limited vertical profiles.

Since the mean transport decline of the cable data over the last decade as expressed in the EMD residual is consistent with the change of Gulf Stream MSL gradient in the Middle Atlantic Bight as found by Ezer et al. (2013), with a reduction in AMOC since 2004 (Robson et al., 2014; Smeed et al., 2014), and also with coastal MSL anomalies in South Florida (discussed below), there is observational evidence to support a recent decline in mean transport as detected in the cable data and we will focus on it in the remainder of the analysis.

\section{Climate indices}

The El Niño-Southern Oscillation (ENSO), NAO, and AMO express global teleconnections influencing atmospheric and oceanic circulation, as well as coastal sea levels. We examine each of these in relation to the Florida Current transport in the following sections. NAO data are available at www.cpc.ncep. noaa.gov/products/precip/CWlink/pna/nao.shtml, AMO data at www.esrl.noaa.gov/psd/data/timeseries/AMO/, and the multivariate ENSO index (MEI) at www.esrl.noaa.gov/psd/ enso/mei/.

\subsection{North Atlantic Oscillation}

Barringer and Larsen (2001) noted that decadal changes in transport were inversely correlated to the NAO index over the period 1982-1998, motivating DeNezio et al. (2009) to propose that wind-stress curl forcing of fast propagating Rossby waves was a causative mechanism. Concurrently, Peng et al. (2009) suggested that the correlation is phase dependent such that a strong positive NAO initiates a transport peak in May, while a strong negative NAO delays the transport peak until July, and concluded that transport variability is influenced by variability of internal ocean dynamics forced by NAO, rather than by NAO directly. More recently, Meinen et al. (2010) examined a longer data record (through 2007) than available to Barringer and Larsen (2001), concluding that the NAOtransport correlation is not evident outside the 1982-1998 time frame, and the mechanism proposed by DeNezio et al. (2009) may be only one of several mechanisms contributing to interannual and longer variability in the Florida Current.

A comparison of EMD residual trends, as well as decadal and interannual IMFs of Florida Current, NAO, AMO, and MEI climate indices are shown in Fig. 3. There does not appear to be relationship between EMD residuals of Florida Current and NAO; however in (b) we identify decadal-scale IMFs of Florida Current and NAO which are approximately anti-phased from 1985-2006, while beyond 2006 the NAO mode appears to be increasing in period and decreasing in amplitude. We note that Meinen et al. (2010) made their determination of NAO and transport synchronization by comparison of 3 and 5 year centered means (their Fig. 7). Examination of their 5 year mean timeseries suggests a stable anti-correlation from 1986 to 2002. Since an arithmetic mean cannot discriminate contributions to the mean from longer period cycles, it may be that decadal-scale IMFs provide a more complete representation of decadal cycles, and is perhaps why we find the anti-correlation to hold beyond 2002. Nonetheless, the finding by Meinen et al. (2010) that a synchronous relation between transport and NAO on decadal timescales is not persistent is supported by our EMD analysis.

\subsection{Atlantic Multidecadal Oscillation}

The AMO is coherently related to North Atlantic coastal MSL anomalies (Frankecombe and Dijkstra, 2009; Park and Dusek, 2013) and it has been suggested that it is a manifestation of the AMOC (Knight et al., 2005; Latif et al., 2004). Since the Florida Current is a component of the AMOC, we examine EMD residuals and decadal IMFs of Florida Current and AMO index in Fig. 3c and d. While there is no clear association between the Florida Current and AMO EMD residuals, there appears to be a link between decadal modes with Florida Current transport leading the AMO index by an average of 1.7 years. This is physically reasonable since the 

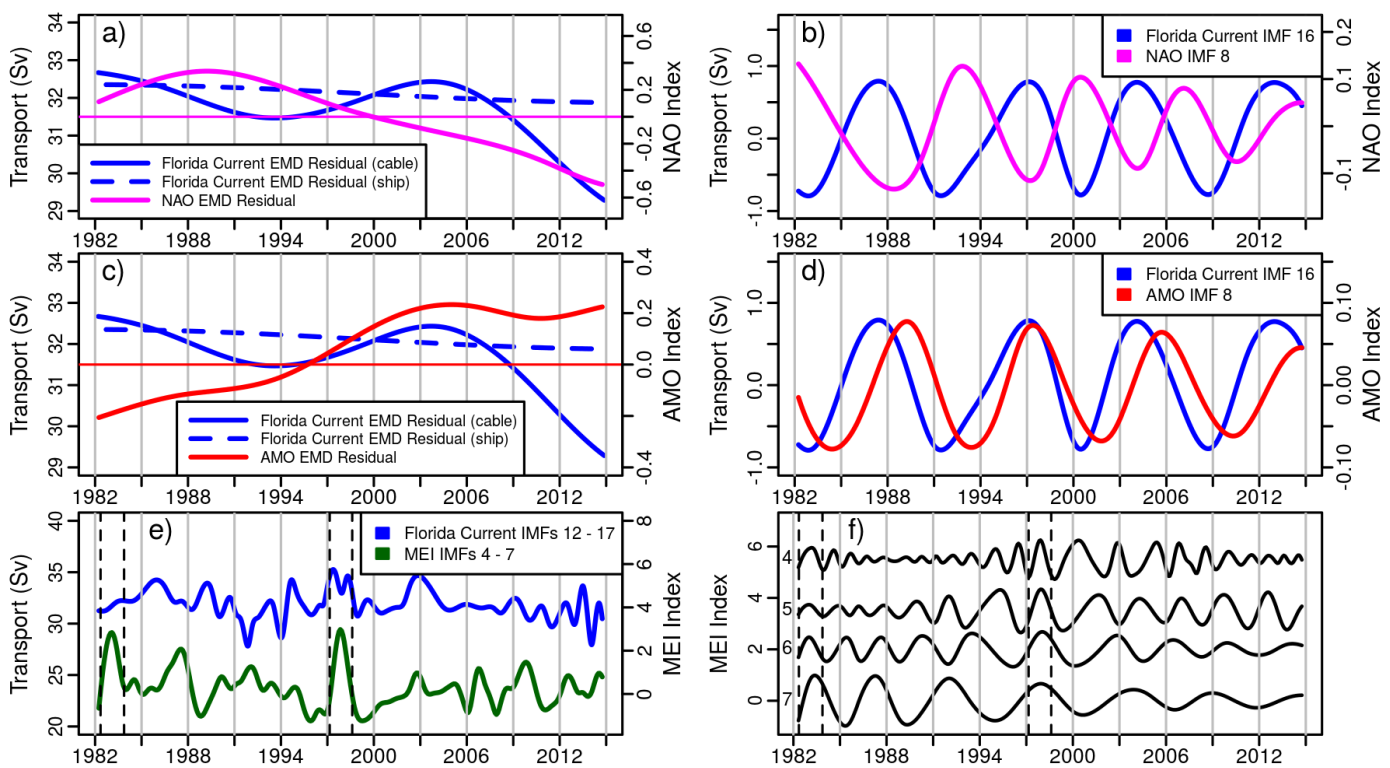

Figure 3. Comparison of Florida Current IMFs with the NAO, AMO, and MEI indices. (a) Florida Current and NAO index EMD residuals. (b) Decadal-scale IMFs of Florida Current $\left(N_{\mathrm{IMF}}=17\right)$ and NAO index $\left(N_{\mathrm{IMF}}=10\right)$. (c) Florida Current and AMO index EMD residuals. (d) Decadal-scale IMFs of Florida Current and AMO index $\left(N_{\mathrm{IMF}}=9\right)$ ). (e) Sum of Florida Current IMFs 12-17 (blue) and sum of MEI IMFs 4-7 (green; $N_{\mathrm{IMF}}=9$ ). (f) MEI IMFs 4-7. IMFs are vertically offset for clarity. The dashed vertical lines in (e and f) bracket strong El Niño events in June 1982-October 1983, and March 1997-August 1998.

Florida Current transports warm water into the North Atlantic.

\subsection{El Niño-Southern Oscillation}

Regarding interannual scales, the ENSO globally influences oceanic processes and is readily apparent in geostrophic transport time series spectra of the Florida Current (NOAA, 2015b). We note a positive Florida Current anomaly coincident with the strong 1997-1998 El Niño in Figs. 2 and 3e; however, there is no evidence of a Florida Current anomaly during the 1982-1983 El Niño suggesting that ENSO influence on Florida Current transport is indirect and only one component of a complex system.

It is also interesting to note that inspection of MEI IMFs during the 1982-1983 and 1997-1998 El Niño events indicate that strong El Niño events correspond to a synchronization of MEI IMFs 4-7 as shown between the vertical dashed lines in Fig. 3f. While this observation does not appear to be directly relevant to the MSL-transport link, it may nonetheless provide a useful starting point for investigations of physical forcings associated with the respective IMFs and their episodic synchronization into El Niño events.

\section{Sea level}

Rising sea levels are a major concern from both ecological and sociological perspectives, and understanding impacts from Florida Current variability can provide valuable infor- mation for modeling efforts and decision makers. Figure 4 plots monthly mean sea levels from March 1982 to October 2014 from the NOAA tide gauge at Vaca Key, Florida, from January 1994 to January 2015 at the Virginia Key, Florida, NOAA gauge (data and station information available at tidesandcurrents.noaa.gov), and from October 1993 to October 2014 at a National Park Service station in Florida Bay within the Everglades National Park (Little Madeira Bay; $25.17580^{\circ} \mathrm{N}, 80.63269^{\circ} \mathrm{W}$ ).

Linear sea level rise (SLR) rates are traditionally estimated from regression of monthly means with the seasonal cycles removed (Zervas, 2009), and are shown with dashed lines. However, in the EMD of sea level we do not alter the data, but use the monthly means as shown in Fig. 4 with no corrections applied. The EMD will partition seasonal cycles into appropriate IMFs including effects from barometric pressure and teleconnections such as ENSO. As discussed below, this has the advantage of not assuming stationarity of the seasonal cycle, which is implicit in the standard approach for linear rate estimates (Zervas, 2009). We also do not alter the data for vertical land movement, which in the case of South Florida is estimated to be a small fraction of a millimeter per year (Snay et al., 2007). The resultant EMD residuals are shown in Fig. 4 with the solid red (Vaca Key), blue (Florida Bay), and green (Virginia Key) curves, suggesting SLR rates above the linear trend over the last decade. 

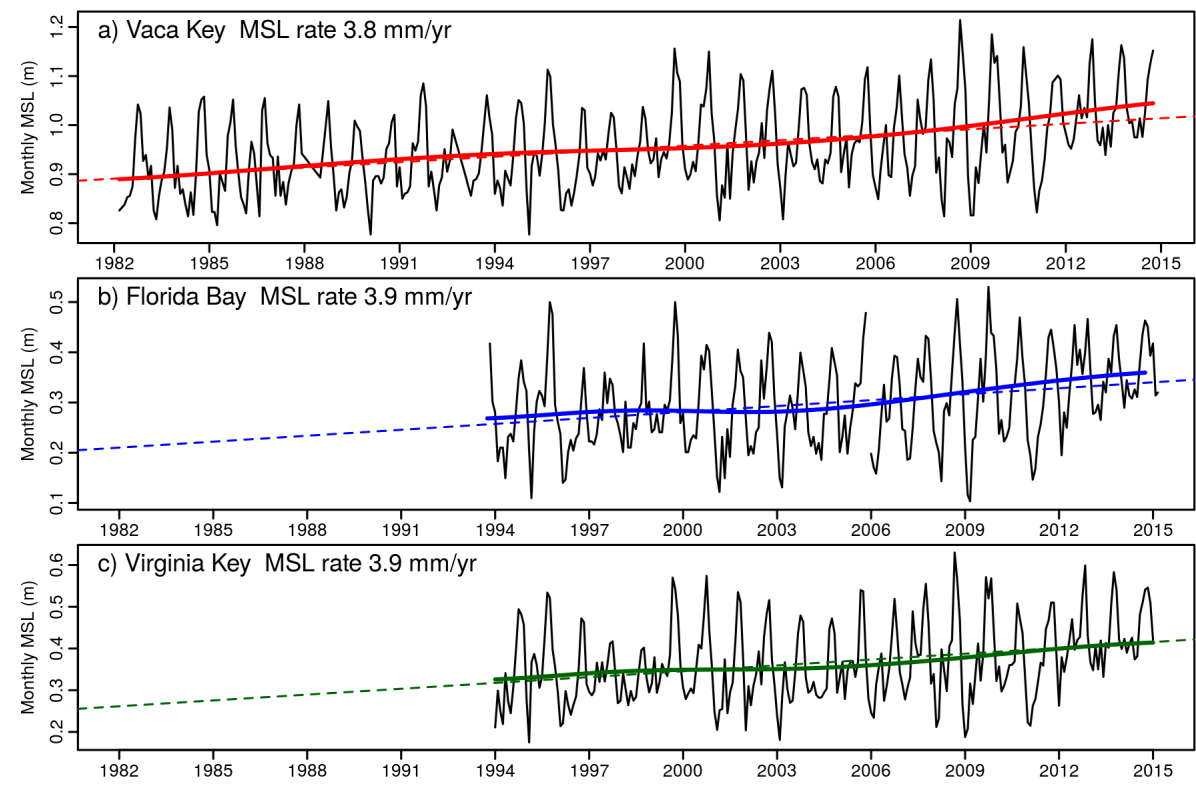

Figure 4. Monthly mean sea levels at (a) Vaca Key, (b) Florida Bay, and (c) Virginia Key, Florida. Solid lines show the EMD residual (red at Vaca Key, blue in Florida Bay, green at Virginia Key), dashed lines plot linear regression of the monthly mean sea level with the annual cycle removed.

Table 3. Linear models of mean sea level rise. EMD is the linear regression of the MSL EMD residual with the Florida Current transport estimate removed.

\begin{tabular}{rrr}
\hline Station & Traditional $\left(\mathrm{mm} \mathrm{yr}^{-1}\right)$ & EMD $\left(\mathrm{mm} \mathrm{yr}^{-1}\right)$ \\
\hline Vaca Key & $3.8 \pm 0.4$ & $3.5 \pm 0.01$ \\
Florida Bay & $3.9 \pm 0.6$ & $3.0 \pm 0.03$ \\
Virginia Key & $3.9 \pm 0.8$ & $2.7 \pm 0.04$ \\
\hline
\end{tabular}

The Florida Current influences coastal sea levels through a geostrophic balance of transport and MSL:

$\Delta \zeta=\frac{-f L}{g} \bar{V}_{s}$,

where $\Delta \zeta$ is the change in sea surface height across the width of the channel $L, f$ the Coriolis parameter, $g$ the vertical acceleration, and $\bar{V}_{s}$ the mean transport velocity (Wunsch et al., 1969). The cross sectional area of the Florida Straits at $27^{\circ} \mathrm{N}$ is approximately $42.96 \mathrm{Mm}^{2}$ and with a nominal transport of $32 \mathrm{~Sv}$ results in a mean current of $0.745 \mathrm{~m} \mathrm{~s}^{-1}$ and an equivalent $1 \mathrm{~Sv}$ current of $0.023 \mathrm{~m} \mathrm{~s}^{-1}$. Evaluating Eq. (1) at $27^{\circ} \mathrm{N}(L=90 \mathrm{~km})$ with a mean current of $\bar{V}_{s}=0.023 \mathrm{~m} \mathrm{~s}^{-1}$ results in a MSL factor of $-1.4 \mathrm{~cm} \mathrm{~Sv}^{-1}$. This of course neglects nonlinear effects and assumes a barotropic uniform flow. We note that this result of $-1.4 \mathrm{~cm} \mathrm{~Sv}^{-1}$ is similar to model-based estimates of MOC transport-MSL adjustment by Woodworth et al. (2014) who found a relation of $-1.5 \mathrm{~cm} \mathrm{~Sv}^{-1}$ along the northeast American Atlantic coast north of Cape Hatteras in the absence of wind forcing.
Leaman et al. (1987) assessed variability of the Florida Current finding that while the northward component of flow is not homogeneous across the strait, the flow is well structured with northward components more than an order of magnitude stronger than eastward components, with standard deviations typically $20 \%$ or less of the mean flow velocity. They also found that barotropic modes dominate over baroclinic modes, with good coherence between the spatial structure of density $\left(\sigma_{T}\right)$ and temperature across the straits. This suggests that the assumption of uniform barotropic flow is reasonable for first-order estimates of transport.

Figure 5a plots sea surface height anomaly (demeaned EMD residual) at Vaca Key, Florida Bay, and Virginia Key, as well as an estimated MSL anomaly for the Florida Current at $27^{\circ} \mathrm{N}$ computed from the Florida Current demeaned EMD residual multiplied by $-1.4 \mathrm{~cm} \mathrm{~Sv}^{-1}$. Subtraction of this Florida Current MSL anomaly (black curve) from the tide gauge anomalies are shown in Fig. $5 \mathrm{~b}$ providing an estimate of the component of SLR not attributed to Florida Current transport, where we have assumed that the transportMSL relationship deduced at $27^{\circ} \mathrm{N}$ applies at the tide gauges. We note that 4 found that the regional dynamic topography of MSL between the cable and tide gauges is relatively uniform, indicating that this region of the Florida Straits responds uniformly to dynamic MSL changes. The dashed lines in Fig. 5b plot linear regressions to the MSL changes with the transport changes removed. Linear rates for the traditional MSL rise and EMD-based estimates with the transport component removed are listed in Table 3. 


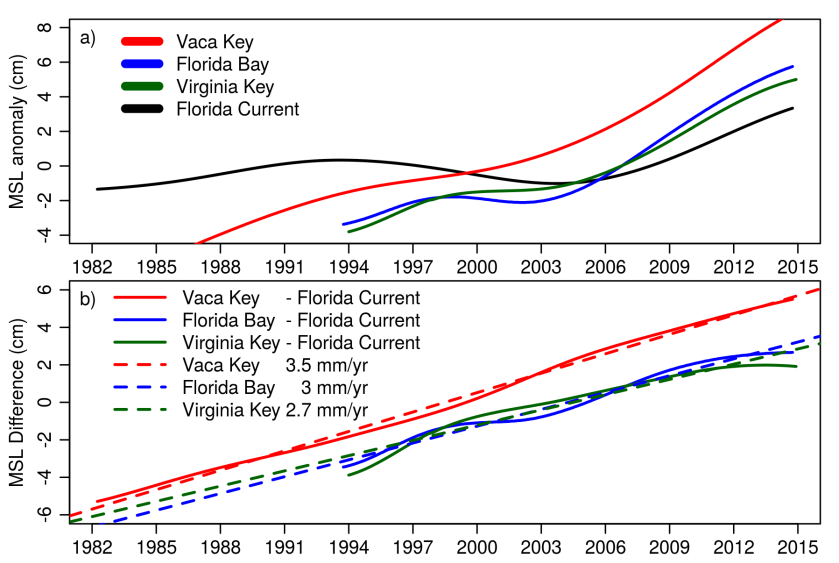

Figure 5. (a) MSL anomalies at Vaca Key, Florida Bay, and Virginia Key from EMD residuals, and for the Florida Current at $27^{\circ} \mathrm{N}$ assuming a MSL-transport rate of $-1.4 \mathrm{~cm} \mathrm{~Sv}^{-1}$. (b) Difference of the Florida Current MSL anomaly from the MSL anomalies at Vaca Key, Florida Bay, and Virginia Key. Dashed lines are linear regressions to the MSL differences.

A noticeable feature of MSL with the Florida Current transport estimate removed is the essentially linear growth of MSL. This suggests that the recent acceleration of the MSL evident in Fig. 4 is primarily due to a decline in Florida Current transport. Specifically, from October 2004 to October 2014 the Vaca Key, Florida Bay, and Virginia Key MSL EMD residuals increased by $7.4,7.1$ and $5.9 \mathrm{~cm}$, respectively, while the estimated MSL increase from the EMD residual of Florida Current transport is $4.3 \mathrm{~cm}$, which is 58,60 , and $73 \%$ of the respective MSL rise at each station. Compared to the long-term linear rates of 3.8 and $3.9 \mathrm{~mm} \mathrm{yr}^{-1}$, MSL rises of $7.4,7.1$, and $5.9 \mathrm{~cm}$ over a decade are roughly twice the linear rate.

\subsection{Seasonal cycle}

The seasonal cycle of MSL that is removed from the monthly means in order to estimate a long-term linear rate (Fig. 4) is computed as an average of the monthly mean sea level for each month over the period of record, assuming that the cycle is stationary in frequency and amplitude. Given that the seasonal anomalies are influenced by atmospheric pressure, ocean temperature, salinity, and transport, an assumption of stationarity may be questionable. Regarding Florida Current transport, Meinen et al. (2010) found that $9 \%$ of the total variance resides in the annual timescale, with significant variability in the structure of the annual cycle across different years. We expect that these annual cycles should be linked through the transport-MSL relation, and from a linear perspective cross-correlation of the stationary seasonal MSL cycle at Vaca Key (NOAA, 2015c) with IMF 11 of Florida Current transport which captures the annual timescale, results in a correlation coefficient of -0.34 significant at the $99.9 \%$ level with a lag of 3 months. This weak anti-correlation sug-
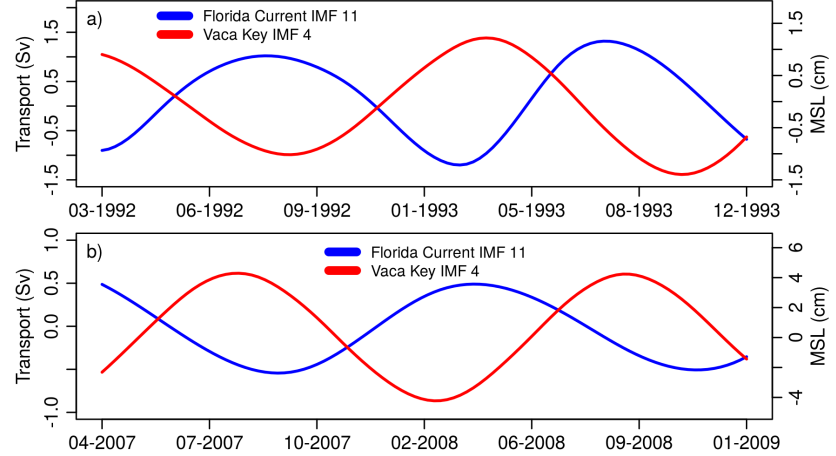

Figure 6. Florida Current transport $\left(N_{\mathrm{IMF}}=17\right)$ and Vaca Key MSL $\left(N_{\mathrm{IMF}}=9\right)$ IMFs with Hilbert spectrum instantaneous frequencies between 9 and 15 months. (a) March 1992December 1993; (b) April 2007-January 2009.

gests some influence between transport and MSL; however, the 3 month time lag does not clearly indicate the expected anti-phased timing of MSL and transport over the annual cycle.

To examine this relation without the assumption of stationarity we identify Vaca Key MSL and Florida Current transport IMFs with Hilbert instantaneous frequencies corresponding to periods between 9 and 15 months. A comparison of portions of Vaca Key IMF 4, and Florida Current IMF 11 which meet this criteria are shown in Fig. 6. Here we note a general inverse relationship between transport and MSL on the annual scale, with cross-correlations between transport and MSL of -0.86 and -0.92 significant at the $99.9 \%$ level with a lag of 6 months. Here, the transport and MSL are antiphased over the annual cycle as expected, more clearly supporting the idea that Florida Current transport is an influence on MSL in the Florida Straits on annual timescales.

\section{Conclusions}

Florida Current transport is dynamically linked to coastal sea level anomalies through geostrophic balance between MSL and mass transport. Empirical mode decomposition of daily transport estimates indicates a $\pm 1 \mathrm{~Sv}$ variation in mean transport from 1982 to 2004, but a $3 \mathrm{~Sv}$ decline from 2004 to 2014; however, direct measurement of velocities from ship surveys lack this dramatic decline over the last decade. This conflict needs resolution to better understand geophysical processes and measurement accuracies associated with Florida Current transport. Nonetheless, the decline suggested by the cable data are consistent with changes in Middle Atlantic Bight MSL gradient, sea level rise at Vaca Key, Florida Bay, Virginia Key, and a decline in AMOC since 2004.

Examination of concurrent NAO and Florida Current decadal modes for 1982-2014 is consistent with the analysis of Meinen et al. (2010) which considered data for 19822007 and found that outside the 1982-1998 window the 
anti-correlation between Florida Current transport and NAO does not appear to hold. However, their centered-average approach could include effects from longer period cycles whereas an IMF will not, and we find that decadal IMFs are approximately in anti-phase synchronization from 1985 to 2006. While there is some tension between these estimates, they both support the notion that the NAO and Florida Current transport are not perennially anti-correlated on decadal timescales.

Regarding sea surface temperatures, we find that decadal modes of the Florida Current lead the AMO index by an average of 1.7 years. Since decadal MSL anomalies along the southeastern US coast are coherent with the AMO index (Park and Dusek, 2013), a connection to Florida Current transport with a reasonable lead time may prove useful for prognosis of long-term MSL anomalies along the coast. One must be cautious that both the NAO and AMO relationships encompass only a few cycles in the data, there is no reason to warrant that these relationships will be maintained. Influences of ENSO are confusing at best. The 1982-1983 El Niño was not observed to be coincident with a Florida Current anomaly, whereas the 1997 event was.

EMD residuals of monthly mean sea levels at Vaca Key, Florida Bay, and Virginia Key indicate an acceleration of sea level over the last decade coincident with the mean transport decline detected in the cable data. To estimate the transportMSL relationship at $27^{\circ} \mathrm{N}$, we neglected nonlinear effects and assumed a barotropic uniform flow across the channel. We further assumed that the transport-MSL relationship deduced at $27^{\circ} \mathrm{N}$ applies at the tide gauges. These assumptions allow for a simple model, but clearly there are points of deficiency. Further work is needed to validate or repudiate them.

The transport-MSL relationship of $-1.4 \mathrm{~cm} \mathrm{~Sv}^{-1}$ was used to estimate the MSL anomaly at $27^{\circ} \mathrm{N}$ based on the EMD residual of Florida Current transport, which when subtracted from the EMD residual MSL largely recovers the long-term linear trend suggesting that the recent acceleration of MSL in South Florida is linked to a decline in Florida Current transport. If this mechanism is causative, it suggests that $60 \%$ of the roughly $7 \mathrm{~cm}$ MSL change in South Florida over the last decade could be related to a mean decline in Florida Current transport. Examination of annual modes of transport and MSL with instantaneous frequencies corresponding to periods between 9 and 15 months finds the expected inverse transport-MSL relationship, suggesting that the seasonal cycle in MSL is influenced by transport variability.

It must be noted that even if the $3 \mathrm{~Sv}$ mean transport detected here in the cable data is verified, we cannot say whether or not this represents a secular climatic shift or the result of natural variability. Kopp (2013) reminded us that at least another decade of MSL observations are needed in the Middle Atlantic Bight to separate detected accelerations from 20th century variability, and Haigh et al. (2014) found that several decades may be required before acceleration detection methods reveal discernible accelerations in individual tide gauge records here, primarily due to the considerable interannual to multidecadal variability of oceanic processes.

Acknowledgements. The Florida Current cable and section data are made freely available on the Atlantic Oceanographic and Meteorological Laboratory web page (www.aoml.noaa.gov/phod/floridacurrent/) and are funded by the NOAA Climate Observation Division.

Edited by: J. M. Huthnance

\section{References}

Barringer, M. O. and Larsen, J. C.: Sixteen years of Florida Current transport at $27^{\circ} \mathrm{N}$, Geophys. Res. Lett., 28, 3179-3182, 2001.

Blaha, J. P.: Fluctuations of monthly sea level as related to the intensity of the Gulf Stream from Key West to Norfolk, J. Geophys. Res., 89, 8033-8042, 1984.

Brunnabend, S.-E., Dijkstra, H. A., Kliphuis, M. A., van Werkhoven, B., Bal, H. E., Seinstra, F., Maassen, J., and van Meersbergen, M.: Changes in extreme regional sea surface height due to an abrupt weakening of the Atlantic meridional overturning circulation, Ocean Sci., 10, 881-891, doi:10.5194/os-10-881-2014, 2014.

Chrystal, G.: On the hydrodynamical theory of Seiches, T RSE Earth, 41, 599-649, doi:10.1017/S0080456800035523, 1906.

DeNezio, P. D., Gramer, L. J., Johns, W. E., Meinen, C. S., and Barringer, M. O.: Observed interannual variability of the Florida Current: wind forcing and the North Atlantic Oscillation, J. Phys. Oceanogr., 39, 721-736, 2009.

Ezer, T., Atkinson, L. P., Corlett, W. B., and Blanco, J. L.: Gulf Stream's induced sea level rise and variability along the U.S. mid-Atlantic coast, J. Geophys. Res.-Oceans, 118, 685-697, 2013.

Ezer, T.: Detecting changes in the transport of the Gulf Stream and the Atlantic overturning circulation from coastal sea level data: The extreme decline in 2009-2010 and estimated variations for 1935-2012, Global and Planet. Change, 129, 23-36, doi:10.1016/j.gloplacha.2015.03.002, 2015.

Frankecombe, L. M. and Dijkstra, H. A.: Coherent multidecadal variability in North Atlantic sea level, Geophys. Res. Lett., 36, L15604, doi:10.1029/2009GL039455, 2009.

Garcia, R. F. and Meinen, C. S.: Accuracy of Florida Current volume transport measurements at $27^{\circ} \mathrm{N}$ using multiple observational techniques, J. Atmos. Ocean. Tech., 31, 1169-1180, 2014.

Goddard, P. B., Yin, J., Griffies, S., and Zhang, S.: An extreme event of sea-level rise along the Northeast coast of North America in 2009-2010, Nat Commun., 6, 6346, doi:10.1038/ncomms7346, 2015.

Haigh, I. D., Wahl, T., Rohling, E. J., Price, R. M., Pattiaratchi, C. B., Calafat, F. M., and Dangendorf, F.: Timescales for detecting a significant acceleration in sea level rise, Nat. Commun., 5, 1-11, 2014.

Higginson Higginson, S., Thompson, Y, Woodworth, P. L. and Hughes C. W.: The tilt of mean sea level along the east coast of North America, Geophys. Res. Lett., 42, 1471-1479, doi:doi:10.1002/2015GL063186. 2015. 
Huang, N. E. and Wu, Z.: A review on Hilbert-Huang transform: method and its applications to geophysical studies, Rev. Geophys., 46, RG2006, doi:10.1029/2007RG000228, 2008.

Jackson, L., Kahana, R., Graham, T., Ringer, M., Woollings, T., Mecking, J., and Wood, R.: Global and European climate impacts of a slowdown of the AMOC in a high resolution GCM, Clim. Dynam., 44, 1-18, doi:10.1007/s00382-015-2540-2, 2015.

Knight, J. R., Allan, R. J., Folland, C. K., Vellinga, M., and Mann, M. E.: A signature of persistent natural thermohaline circulation cycles in observed climate, Geophys. Res. Lett., 32, L20708, doi:10.1029/2005GL024233, 2005.

Kopp, R. E.: Does the mid-Atlantic United States sea level acceleration hot spot reflect ocean dynamic variability?, Geophys. Res. Lett., 40, 3981-3985, 2013.

Latif, M., Roeckner, E., Botzet, M., Esch, M., Haak, H., Hagemann, S., Jungclaus, J., Legutke, S., Marsland, S., Mikolajewicz, U., and Mitchell, J.: Reconstructing, monitoring and predicting decadal-scale changes in the North Atlantic thermohaline circulation with sea surface temperature, J. Climate, 17, 1605-1614, 2004

Leaman, K. D., Molinari, R., and Vertes, P.: Structure and variability of the Florida Current at $27^{\circ} \mathrm{N}$ : April 1982-July 1984, J. Phys. Oceanogr., 17, 566-583, 1987.

Liu, Y., Lee, S.-K., Enfield, D. B., Muhling, B. A., Lamkin, J. T., Muller-Karger, F. E., and Roffer, M. A.: Potential impact of climate change on the Intra-Americas Sea: Part-1. A dynamic downscaling of the CMIP5 model projections, J. Marine Syst., 148, 56-69, 2015.

Haigh, I., Hirschi, J., Grist, J. and Smeed, D.: Ocean impact on decadal Atlantic climate variability revealed by sea-level observations, Nature, 521, 508-510, doi:10.1038/nature14491, 2015.

Meinen, C. S., Barringer, M. O., and Garcia, R. F.: Florida Current transport variability: an analysis of annual and longer-period signals, Deep-Sea Res. Pt. I, 57, 835-846, 2010.

Montgomery, R. B.: Fluctuations in monthly sea level on Eastern U.S. coast as related to dynamics of western North Atlantic Ocean, J. Mar. Res., 1, 165-185, 1938.

NOAA: Western Boundary Time Series, Florida Current Transport Time Series and Cruises, available at: http://www.aoml.noaa. gov/phod/wbts/index.php, last access: 24 April 2015, 2015a.

NOAA: Florida Current spectral analysis, available at: http://www. aoml.noaa.gov/phod/altimetry/cvar/fl/spectra.php, last access: 24 April 2015, 2015b.

NOAA: Average Seasonal Cycle, 8723970 Vaca Key, Florida, available at: http://tidesandcurrents.noaa.gov/sltrends/seasonal.htm? stnid=8723970, last access: 11 June 2015, 2015c.

Park, J. and Dusek, G.: ENSO components of the Atlantic multidecadal oscillation and their relation to North Atlantic interannual coastal sea level anomalies, Ocean Sci., 9, 535-543, doi:10.5194/os-9-535-2013, 2013.

Peng, G., Garraffo, Z., Halliwell, G. R., Smedsted, O. M., Meinen, C. S., Kourafalou, V., and Hogan, P.: Temporal Variability of Florida Current Transport at $27^{\circ}$ N, Nova Science Publishers Inc., 2009.
Robson, J., Hodson, D., Hawkins, E., and Sutton, R.: Atlantic overturning in decline?, Nat. Geosci., 7, 2-3, 2014.

Rossby, T., Flagg, C. N., Donohue, K., Sanchez-Franks, A., and Lillibridge, J.: On the long-term stability of Gulf Stream transport based on 20 years of direct measurements, Geophys. Res. Lett., 41, 114-120, 2014.

Sallenger, A. H., Doran, K. S., and Howd, P.: Hotspot of accelerated sea-level rise on the Atlantic coast of North America, Nat. Clim. Change, 2, 884-888, 2012.

Snay, R., Cline, M., Dillinger, W., Foote, R., Hilla, S., Kass, W., Ray, J., Rohde, J., Sella, G., and Soler, T.: Using global positioning system-derived crustal velocities to estimate rates of absolute sea level change from North American tide gauge records, J. Geophys. Res., 112, B04409, doi:10.1029/2006JB004606, 2007.

Smeed, D. A., McCarthy, G. D., Cunningham, S. A., FrajkaWilliams, E., Rayner, D., Johns, W. E., Meinen, C. S., Baringer, M. O., Moat, B. I., Duchez, A., and Bryden, H. L.: Observed decline of the Atlantic meridional overturning circulation 2004-2012, Ocean Sci., 10, 29-38, doi:10.5194/os-10-29-2014, 2014.

Solomon, S., Qin, D., Manning, M., Chen, Z., Marquis, M., Averyt, K. B., Tignor, M., and Miller, H. L. : Climate Change 2007: The Physical Science Basis, Cambridge University Press, Cambridge, UK and New York, NY, USA, 2007.

Sweet, W. V., Zervas, C., and Gill, S.: Elevated East Coast Sea Level Anomaly: June-July 2009, Tech. Report NOS CO-OPS 051, United States Department of Commerce, National Oceanic and Atmospheric Administration, Silver Spring, Maryland, USA, 2009.

Thomas, M. D., de Boer, A. M., Stevens, D. P., and Johnson, H. L.: Upper ocean manifestations of a reducing meridional overturning circulation, Geophys. Res. Lett., 39, L16609, doi:10.1029/2012GL052702, 2012.

Thompson, P. R. and Mitchum, G. T.: Coherent sea level variability on the North Atlantic western boundary, J. Geophys. Res. Oceans, 119, 5676-5689, doi:10.1002/2014JC009999, 2014.

Woodworth, P. L., Morales Maqueda, M.A., Roussenov, V.M., Williams, R.G. and Hughes, C.W.: Mean sea-level variability along the northeast American Atlantic coast and the roles of the wind and the overturning circulation, J. Geophys. Res.-Oceans, 119, 8916-8935, doi:doi:10.1002/2014JC010520, 2014.

Wu, Z., Huang, N. E., Long, S. R., and Peng, C.-K.: On the trend, detrending and variability of nonlinear and non-stationary time series, P. Nat. Acad. Sci. USA, 104, 14889-14894, 2007.

Wunsch, C., Hansen, D. V., and Zetler, B. D.: Fluctuations of the Florida Current inferred from sea level records, Deep-Sea Res., 16, 447-470, 1969.

Zervas, C.: Sea Level Variations of the United States 1854-2006, Tech. Report NOS CO-OPS 053, United States Department of Commerce, National Oceanic and Atmospheric Administration, available at: http://www.tidesandcurrents.noaa.gov/publications/ Tech_rpt_53.pdf (last access: 27 July 2015), 2009. 